\title{
Direct Alcohol Biomarkers Prediction Capacity on Relapse and Mortality in Liver Transplantation Candidates: A Follow-Up Study
}

\author{
Pablo Barrio ${ }^{1, *}$, Oriol Marco ${ }^{2}$, Mauro Druetta ${ }^{2}$, Laia Tardon ${ }^{2}$, Anna Lligonya ${ }^{1}$, Friedrich Martin Wurst ${ }^{3}$, \\ Wolfgang Weinmann ${ }^{4}$, Michel Yegles ${ }^{5}$ and Antoni Gual ${ }^{1} \mathbb{D}$ \\ 1 Grup Recerca Addiccions Clínic (GRAC-GRE), Institut d'Investigacions Biomèdiques August Pi I \\ Sunyer (IDIBAPS), Hospital Clínic Barcelona, Carrer villarroel 170, 08036 Barcelona, Spain; \\ alligona@clinic.cat (A.L.); tgual@clinic.cat (A.G.) \\ 2 Servei de Psiquiatriai Psicologia, Hospital Clínic de Barcelona, 08036 Barcelona, Spain; \\ omarco@clinic.cat (O.M.); maurodruetta@hotmail.com (M.D.); tardon@clinic.cat (L.T.) \\ 3 Psychiatric University Hospital, 4002 Basel, Switzerland; frieder.wurst@gmx.de \\ 4 Institute of Forensic Medicine, University of Bern, 3012 Bern, Switzerland; wolfgang.weinmann@irm.unibe.ch \\ 5 Service de Toxicologie, LaboratoireNational de Santé, 3555 Dudelange, Luxembourg; \\ michel.yegles@Ins.etat.lu \\ * Correspondence: pbarrio@clinic.cat
}

\section{check for}

updates

Citation: Barrio, P.; Marco, O.; Druetta, M.; Tardon, L.; Lligonya, A.; Wurst, F.M.; Weinmann, W.; Yegles, M.; Gual, A. Direct Alcohol Biomarkers Prediction Capacity on Relapse and Mortality in Liver Transplantation Candidates: A Follow-Up Study. Transplantology 2021, 2, 246-252. https://doi.org/ $10.3390 /$ transplantology2030023

Academic Editor: Stefano Gitto

Received: 31 May 2021

Accepted: 21 June 2021

Published: 23 June 2021

Publisher's Note: MDPI stays neutral with regard to jurisdictional claims in published maps and institutional affiliations.

Copyright: (c) 2021 by the authors. Licensee MDPI, Basel, Switzerland. This article is an open access article distributed under the terms and conditions of the Creative Commons Attribution (CC BY) license (https:// creativecommons.org/licenses/by/ $4.0 /)$
Abstract: Liver transplantation is a complex procedure that requires multiple evaluations, including abstinence monitorization. While literature assessing the impact of different variables on relapse, survival, and graft loss exists, little is known about the predictive capacity of direct alcohol biomarkers. The primary aim of this study was to evaluate the prediction capacity of direct alcohol biomarkers regarding patient survival and clinical relapse. We hypothesized that patients screening positive for any of the experimental biomarkers would show an increased risk of clinical alcohol relapse and death. We conducted a retrospective data recollection from medical files of patients awaiting liver transplantation, who were at baseline screened with Peth, EtG in hair and urine, and EtS. We tested the prediction capacity of the biomarkers with two Cox-regression models. A total of 50 patients were included $(84 \%$ men, mean age 59 years $(S D=6))$. Biomarkers at baseline were positive in 18 patients. The mean follow-up time for this study was 26 months (SD = 10.4). Twelve patients died, liver transplantation was carried out in 12 patients, and clinical relapse was observed in eight patients. The only significant covariate in the Cox-regression models was age with clinical relapse, with younger patients being at greater risk of relapse. This study could not find a significant prediction capacity of direct alcohol biomarkers for mortality or clinical relapse during follow-up. Higher sample sizes might be needed to detect statistically significant differences. All in all, we believe that direct alcohol biomarkers should be widely used in liver transplantation settings due to their high sensitivity for the detection of recent drinking.

Keywords: alcohol biomarkers; liver transplantation; alcohol dependence

\section{Introduction}

Liver transplantation is a complex procedure that requires multiple evaluations before and after the surgical replacement [1,2]. In alcoholic cirrhosis, abstinence monitorization can be considered one of the key assessments [3,4].

Graft loss and increased mortality have been postulated as the main reasons supporting the need for complete abstinence [5,6]. In this respect, previous literature clearly supports the link between alcohol relapse and a worsened prognosis [5]. This also explains the introduction of the 6-months rule [7].

Abstinence assessment relies fundamentally on both self-reports and biomarkers, wherein information provided by the two must be taken into account. Regarding biomark- 
ers, direct alcohol ones have widely replaced the long-standing indirect biomarkers, since they have repeatedly shown a much better validity, with increased specificity and sensitivity [8-10].

The overall impact of abstinence on liver outcomes seems to be clearly defined [11,12]). Notwithstanding, the individual significance of a positive alcohol screening during the evaluation procedure remains to be elucidated. While abundant literature assessing the impact of different variables on relapse, survival, and graft loss exists [13-18], little is known about the predictive capacity of direct alcohol biomarkers, a fact not exclusively related to LT populations [19].

Based on a previous study where a cohort of liver transplant candidates were transversally evaluated with phosphatidylethanol, EtG, Ets, and hair EtG [20], here we aimed to prospectively evaluate the prediction capacity of biomarker results regarding patient survival and clinical relapse. It is important to note that the biomarker results from our previous study were not made available to either patients or professionals. This means our results did not influence the natural evolution of the process. We hypothesized that patients screening positive for any of the experimental biomarkers would show an increased risk of clinical alcohol relapse, death, and graft loss in case of transplantation.

\section{Methods}

\subsection{Study Design and Subjects}

We performed a retrospective data recollection from patients' medical files. Subjects were alcohol use disorder patients undergoing psychiatric evaluation before being included in the liver transplant waiting list. Importantly, having been deemed suitable for liver transplantation did not mean that the procedure was imminent, but depended on patient clinical status and evolution. This study was approved by the local IRB.

\subsection{Procedure and Outcome Selection}

At baseline, patients completed the AUDIT-C and the TLFB for the previous month. The AUDIT is a 10-item screening tool widely used to assess drinking amount, frequency, and consequences. For screening purposes, a cut-off of 8 is normally established between low and medium risk. The TLFB is a calendar method used to retrospectively record all the alcohol units ingested in the preceding 28 days. Both instruments have been widely validated in addiction and hospital settings [21,22]. Patients provided a hair sample (if available), a urine specimen, and a blood sample. In urine, EtG and EtS were investigated. EtG was also evaluated in hair. PEth was measured in blood with dried blood spot cards. A complete report of the methodology for biomarker assessment can be found in a previous publication [20]. Experimental biomarker results were not made available to the patient or the treating professional.

After the baseline assessments patients continued to receive their usual treatment and appointments related to the liver transplant procedure (which usually includes EtG testing with immunoenzymatic assays). Patients also kept regular appointments with their regular psychiatrist and/or psychologist as part of their routine treatment. For this follow-up study, the following variables were collected from patients' medical records: survival status, whether or not patients had a liver transplant, and whether or not patients relapsed into overt alcohol drinking. Alcohol relapse was operationalized as any sign in the patients' medical records suggesting alcohol intake, i.e., a positive self-report, a positive biomarker, or a visit to any medical service due to alcohol consumption.

\subsection{Statistical Analysis}

We conducted a survival analysis as the main methodology of the study. We were interested in the prediction capacity of the biomarker results for both mortality and relapse rates. Therefore, we conducted two Cox-regression models. In the first, survival status (dead/alive) was the dependent variable. Included covariates were age, sex, biomarker positivity at baseline (considered positive if any of the direct biomarkers used were posi- 
tive), and a history of drug use. For the second model, clinical relapse was the dependent variable. The included covariates were the same as in the first model.

\section{Results}

The baseline sample comprised 50 patients, consecutively included between December 2017 and October 2018 (mean age 59 years $(S D=6)$; 84\% were men). A total of 13 participants had HCV (26\%), and one participant had chronic HBV infection. HIV was present in two patients, and a lifetime history of drug use was recorded in seven patients (14\%). Regarding smoking, 13 patients had never been smokers, 16 patients were current smokers, and 21 were ex-smokers. Meld scores ranged from 6 to 24, with a mean of 12.8 (SD 3.7).

At baseline, self-reports were positive for recent alcohol intake in three patients $(6 \%$ of the total sample). Biomarkers were positive in 18 patients ( $36 \%$ of the total sample). The most frequently positive biomarker was EtS (13 patients), followed by EtG (6 patients) and PEth (5 patients).

The mean follow-up time for this study was 26 months $(\mathrm{SD}=10,4)$. During that time, a total of 12 patients died (Table 1 lists the causes and times of death). Liver transplantation was carried out in 12 patients. None of the deaths occurred in transplanted patients. Clinical relapse was observed in eight patients. All eight patients were male, and none of them had a previous diagnosis of lifetime drug use. Of all relapsed patients, only one had received a liver transplantation.

Table 1. Time and cause of death of deceased patients during follow-up.

\begin{tabular}{cc}
\hline Follow-Up Time (Months) & Cause of Death \\
\hline 1 & Sudden death \\
2 & Septic shock \\
2 & Surgical complications \\
3 & Unknown \\
16 & Cirrhosis \\
19 & Sepsis \\
20 & Hepatic encephalpopathy and upper digestive tractbleeding \\
21 & Hepatocarcinocma \\
24 & Hepatic encephalopathy \\
29 & Hepatic encephalopathy \\
30 & Endocarditis \\
35 &
\end{tabular}

Survival plots using the Kaplan-Meier method for both models according to positive or negative biomarkers at baseline are depicted in Figures 1 and 2. Both log-rank tests showed no significant differences (Figure 1 chi-square 0.350; $p=0.56$; Figure 2 chi-square $0.44 ; p=0.51$ ) The only significant covariate in the Cox-regression models was age for clinical relapse, with younger patients being at greater relapse risk. A detailed result of the models can be seen in Table 2. 


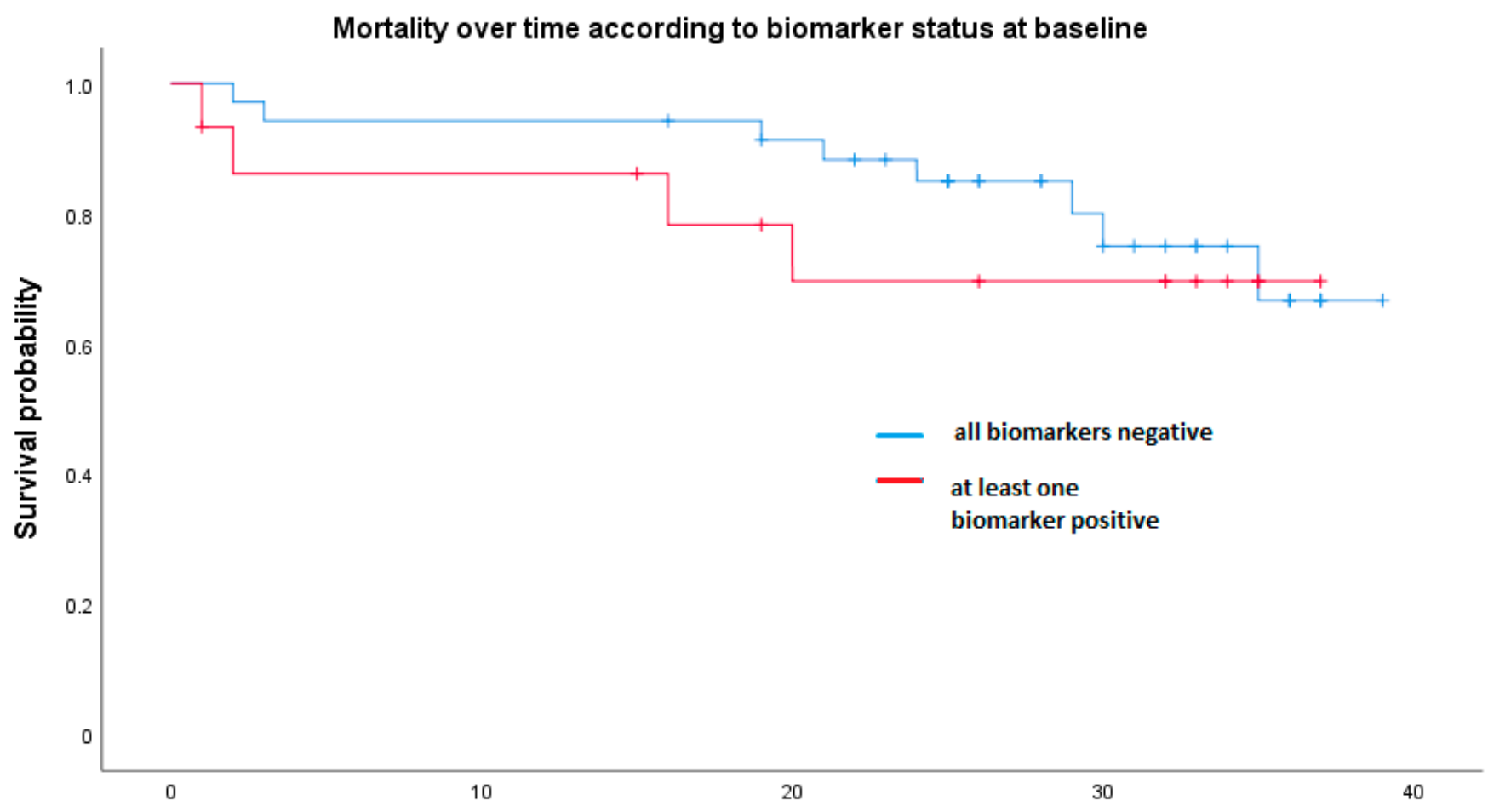

Figure 1. Kaplan-Meier plot depicting survival (in months) according to biomarker status at baseline.

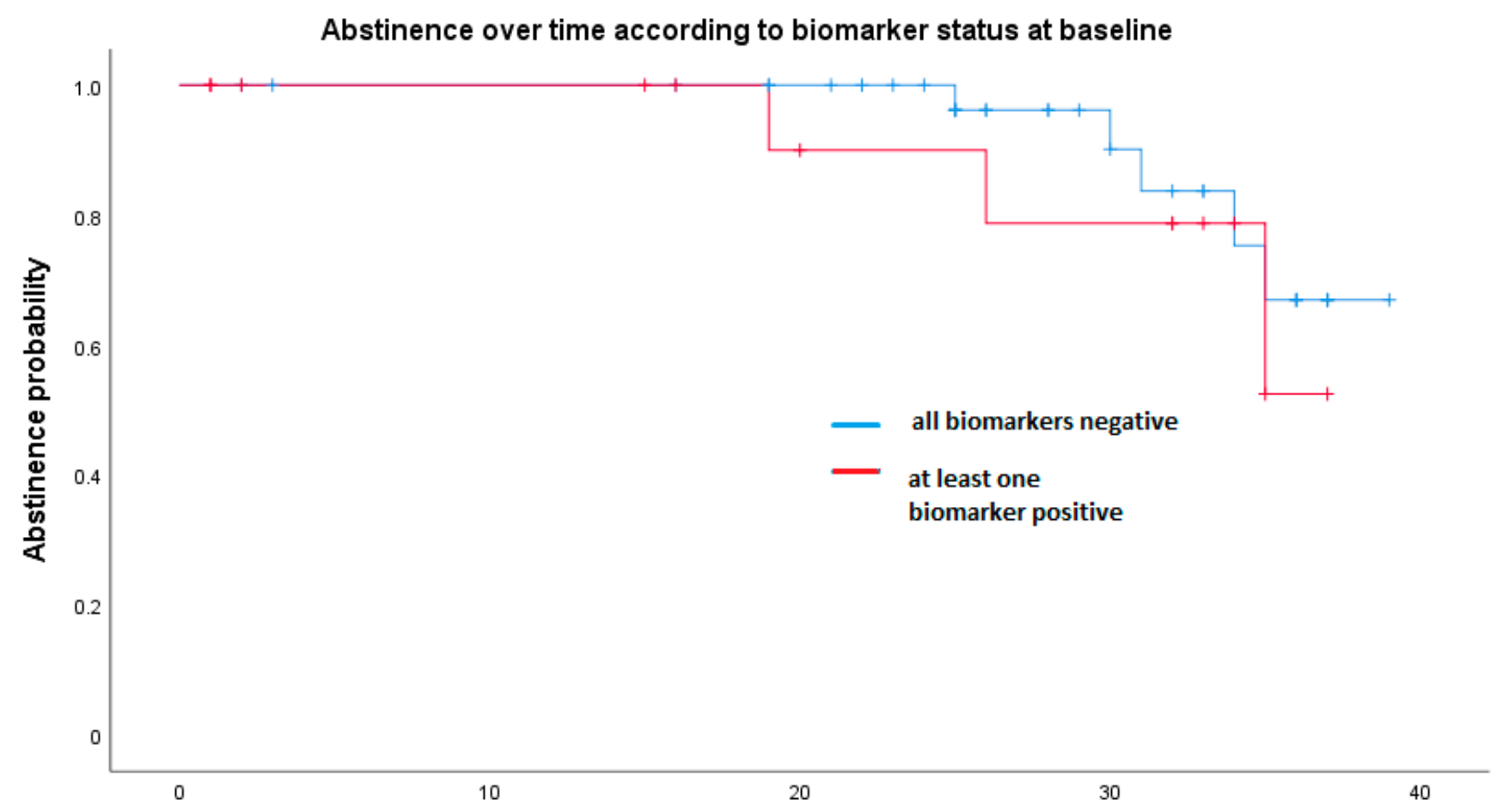

Figure 2. Kaplan-Meier plot depicting abstinence according to biomarker status at baseline. 
Table 2. Cox-regression models.

\begin{tabular}{ccc}
\hline Covariate & $\begin{array}{c}\text { Model 1 (Outcome: } \\
\text { Mortality) }\end{array}$ & $\begin{array}{c}\text { Model 2 (Outcome: Clinical } \\
\text { Relapse) }\end{array}$ \\
\hline Age & $\mathrm{B}=-0.2 ; p=0.562$ & $\mathrm{~B}=-0.27 ; p=0.016$ \\
\hline Sex & $\mathrm{OR}=3.5 ; 95 \%$ CI $0.28-45$ & $\mathrm{OR}=26.7 ; p=0.94$ \\
\hline All biomarkers negative & $\mathrm{B}=-0.6 ; p=0.377$ & $\mathrm{~B}=-1.06 ; p=0.22$ \\
\hline Ever-smoker & $\mathrm{OR}=1.8 ; 95 \%$ CI $0.49-6.6$ & $\mathrm{OR}=0.9 ; 95 \%$ CI $0.15-5.5$ \\
\hline $\begin{array}{c}\text { Duration of reported } \\
\text { abstinence }\end{array}$ & $\mathrm{B}=0.007 ; p=0.43$ & $\mathrm{~B}=-0.02 ; p=0.21$ \\
\hline Lifetime drug use & OR $=0.6 ; 95 \%$ CI $0.08-5.15$ & $*$ \\
\hline
\end{tabular}

\section{Discussion}

This follow-up study did not find a significant prediction capacity of direct alcohol biomarkers for mortality or clinical relapse into alcohol drinking. While the relatively small sample size warrants precaution when interpreting these findings, it appears that our results could be in line with previous publications suggesting that alcohol drinking might not be the leading factor of mortality in liver transplantation cohorts [15,23-26].

Similarly, the duration of reported abstinence had no impact upon the study outcomes. In fact, it has been suggested by previous literature that, in spite of having an impact on short-term relapse outcomes, the duration of reported abstinence prior to LT might lose its effects in the long run [15]

Taken together, these facts lead to one of the main controversies in alcohol-related liver transplantation: the 6-months rule [27] First issued in 1997 by the United Network for Organ Sharing (UNOS), it was strictly adhered to during the following years. However, since the accumulated literature has failed to provide solid evidence supporting the 6 months period, most of the current guidelines approach this somehow arbitrary time frame as a non-absolute contraindication for liver transplantation [28].

Despite the non-significant findings of our study, we believe it is important to highlight the use of direct alcohol biomarkers in liver transplantation studies. It has been repeatedly shown that, when compared to other traditional methods of abstinence assessment (selfreports and indirect biomarkers such as MCV or even ethanol itself in breath or urine), direct alcohol biomarkers noticeably increase the sensitivity for the detection of recent drinking [10,29-31]. Moreover, the relevant of this fact has been shown for a wide variety of populations, including alcohol liver disease [32,33] and transplantation patients [20,34-36]. Proof of this is the high discrepancy between the rate of positive self-reports at baseline (with only 3 patients disclosing drinking) and the high rate of positive biomarkers (up to 18 patients with at least 1 positive biomarker). In this respect, it must be pointed out that most of the studies conducted in liver transplantation populations have relied on self-reports and traditional measures for abstinence assessment. Therefore, it remains to be determined whether the accumulated evidence could indicate different conclusions if abstinence was to be determined with more sensitive instruments. For example, they might allow redefining some relapses after transplantation as covert drinking before the procedure.

Important limitations must be taken into account when interpreting the findings of this study. First, the sample size might have been too small and the follow-up time too short to provide significant results. This means that further studies with prospective designs and sufficient power should be conducted to better understand the possible prognostic significance of direct alcohol biomarkers. Additionally, this was a single-center study, thus probably reducing its external validity. Finally, despite baseline assessments being conducted with direct biomarkers, abstinence during follow-up was measured with clinical records only. Furthermore, in many instances it was not possible to collect the amount 
of drinking. The results might have differed if direct ethanol metabolites had also been applied at follow-up.

In conclusion, and similar to what has been reported in the previous literature, it seems that abstinence prior to liver transplantation should be approached dimensionally instead of categorically. While it seems reasonable to believe that the longer the abstinence, the potentially better the outcomes, the relationship seems, unsurprisingly, far from mathematical. The widespread implementation of direct alcohol biomarkers and other new technologies for the accurate assessment of abstinence and other relevant variables in the selection process warrants further research.

Author Contributions: Conceptualization, P.B. and A.G.; methodology, P.B.; formal analysis, P.B.; investigation, P.B., O.M., M.D., L.T.; data curation, O.M., M.D., A.L.; writing-original draft preparation, P.B.; writing-review and editing, all authors. All authors have read and agreed to the published version of the manuscript."

Funding: This research received no external funding.

Institutional Review Board Statement: The study was conducted according to the guidelines of the Declaration of Helsinki, and approved by the Institutional Review Board of the Hospital Clinic de Barcelona (HCB/2021/0443, 15 April 2021).

Informed Consent Statement: Patient consent was waived due to the retrospective nature of the study.

Data Availability Statement: Not applicable.

Conflicts of Interest: The authors declare no conflict of interest.

\section{References}

1. Beresford, T.P.; Lucey, M.R. Towards standardizing the alcoholism evaluation of potential liver transplant recipients. Alcohol Alcohol. 2018, 53, 135-144. [CrossRef]

2. Telles-Correia, D.; Mega, I. Candidates for liver transplantation with alcoholic liver disease: Psychosocial aspects. World J. Gastroenterol. 2015, 21, 11027-11033. [CrossRef]

3. DiMartini, A.F.; Dew, M.A. Monitoring alcohol use on the liver transplant wait list: Therapeutic and practical issues. Liver Transplant. 2012, 18, 1267-1269. [CrossRef]

4. Staufer, K.; Yegles, M. Biomarkers for detection of alcohol consumption in liver transplantation. World J. Gastroenterol. 2016, 22, 3725-3734. [CrossRef]

5. Kodali, S.; Kaif, M.; Tariq, R.; Singal, A.K. Alcohol relapse after liver transplantation for alcoholic cirrhosis-impact on liver graft and patient survival: A meta-analysis. Alcohol Alcohol. 2018, 53, 166-172. [CrossRef]

6. Rice, J.P.; Eickhoff, J.; Agni, R.; Ghufran, A.; Brahmbhatt, R.; Lucey, M.R. Abusive drinking after liver transplantation is associated with allograft loss and advanced allograft fibrosis. Liver Transplant. Off. Publ. Am. Assoc. Study Liver Dis. Int. Liver Transplant. Soc. 2013, 19, 1377-1386. [CrossRef]

7. Shawcross, D.L.; O'Grady, J.G. The 6-month abstinence rule in liver transplantation. Lancet 2010, 376, 216-217. [CrossRef]

8. Allen, J.P.; Wurst, F.M.; Thon, N.; Litten, R.Z. Assessing the drinking status of liver transplant patients with alcoholic liver disease. Liver Transplant. 2013, 19, 369-376. [CrossRef]

9. Barrio, P.; Wurst, F.M.; Gual, A. New alcohol biomarkers. New challenges. Alcohol Alcohol. 2018, 53, 762-763. [CrossRef]

10. Wurst, F.M.; Thon, N.; Yegles, M.; Schrück, A.; Preuss, U.W.; Weinmann, W. Ethanol metabolites: Their role in the assessment of alcohol intake. Alcohol. Clin. Exp. Res. 2015, 39, 2060-2072. [CrossRef]

11. Dumortier, J.; Dharancy, S.; Cannesson, A.; Lassailly, G.; Rolland, B.; Pruvot, F.R.; Boillot, O.; Faure, S.; Guillaud, O.; RigoleDonnadieu, H.; et al. Recurrent alcoholic cirrhosis in severe alcoholic relapse after liver transplantation: A frequent and serious complication. Am. J. Gastroenterol. 2015, 110, 1160-1166. [CrossRef] [PubMed]

12. Erard-Poinsot, D.; Guillaud, O.; Hervieu, V.; Thimonier, E.; Vallin, M.; Chambon-Augoyard, C.; Boillot, O.; Scoazec, J.Y.; Dumortier, J. Severe alcoholic relapse after liver transplantation: What consequences on the graft? A study based on liver biopsies analysis. Liver Transplant. 2016, 22, 773-784. [CrossRef]

13. Chuncharunee, L.; Yamashiki, N.; Thakkinstian, A.; Sobhonslidsuk, A. Alcohol relapse and its predictors after liver transplantation for alcoholic liver disease: A systematic review and meta-analysis. BMC Gastroenterol. 2019, 19, 150. [CrossRef] [PubMed]

14. Deutsch-Link, S.; Weinrieb, R.M.; Jones, L.S.; Solga, S.F.; Weinberg, E.M.; Serper, M. Prior relapse, ongoing alcohol consumption, and failure to engage in treatment predict alcohol relapse after liver transplantation. Dig. Dis. Sci. 2020, 65, 2089-2103. [CrossRef] [PubMed]

15. Lindenger, C.; Castedal, M.; Schult, A.; Aberg, F. Long-term survival and predictors of relapse and survival after liver transplantation for alcoholic liver disease. Scand. J. Gastroenterol. 2018, 53, 1553-1561. [CrossRef] 
16. Lombardo-Quezada, J.; Colmenero, J.; López-Pelayo, H.; Gavotti, C.; Lopez, A.; Crespo, G.; Lopez, E.; Gual, A.; Lligoña, A.; Navasa, M. Prediction of alcohol relapse among liver transplant candidates with less than 6 months of abstinence using the high-risk alcoholism relapse score. Liver Transplant. 2019, 25, 1142-1154. [CrossRef]

17. Pose, E.; Torrents, A.; Reverter, E.; Perez-Campuzano, V.; Campos-Varela, I.; Avitabile, E.; Gratacós-Ginès, J.; Castellote, J.; Castells, L.; Colmenero, J.; et al. A notable proportion of liver transplant candidates with alcohol-related cirrhosis can be delisted because of clinical improvement. J. Hepatol. 2021. [CrossRef]

18. Satapathy, S.K.; Thornburgh, C.; Heda, R.; Jiang, Y.; Kedia, S.K.; Nair, S.P.; Eason, J.D.; Maluf, D. Predicting harmful alcohol relapse after liver transplant: The HALT score. Clin. Transplant. 2020, 34. [CrossRef]

19. Barrio, P.; Mondon, S.; Teixidor, L.; Ortega, L.; Vieta, E.; Gual, A. One year clinical correlates of EtGpositive urine screening in alcohol-dependent patients: A survival analysis. Alcohol Alcohol. 2017, 52, 460-465. [CrossRef]

20. Barrio, P.; Gual, A.; Lligoña, A.; Teixidor, L.; Weinmann, W.; Yegles, M.; Wurst, F.M. Phosphatidylethanol for monitoring alcohol use in liver transplant candidates: An observational study. J. Clin. Med. 2020, 9, 3060. [CrossRef]

21. Bohn, M.J.; Babor, T.F.; Kranzler, H.R. The Alcohol Use Disorders Identification Test (AUDIT): Validation of a screening instrument for use in medical settings. J. Stud. Alcohol 1995, 56, 423-432. Available online: http://www.ncbi.nlm.nih.gov/pubmed/7674678 (accessed on 31 May 2021). [CrossRef] [PubMed]

22. Sobell, L.C.; Sobell, M.B. Timeline follow-back. In Measuring Alcohol Consumption; Litten, R.Z., Allen, J.P., Eds.; Humana Press: Totowa, NJ, USA, 1992; pp. 41-72. [CrossRef]

23. Björnsson, E.; Olsson, J.; Rydell, A.; Fredriksson, K.; Eriksson, C.; Sjöberg, C.; Olausson, M.; Bäckman, L.; Castedal, M.; Friman, S. Long-term follow-up of patients with alcoholic liver disease after liver transplantation in Sweden: Impact of structured management on recidivism. Scand. J. Gastroenterol. 2005, 40, 206-216. [CrossRef]

24. Kollmann, D.; Rasoul-Rockenschaub, S.; Steiner, I.; Freundorfer, E.; Györi, G.P.; Silberhumer, G.; Soliman, T.; Berlakovich, G.A. Good outcome after liver transplantation for ALD without a 6 months abstinence rule prior to transplantation including post-transplant CDT monitoring for alcohol relapse assessment-A retrospective study. Transpl. Int. 2016, 29, 559-567. [CrossRef] [PubMed]

25. Skladany, L.; Selcanova, S.A.; Koller, T. Alcohol use relapse following liver transplantation for alcoholic liver disease. Ann. Transplant. 2019, 24, 359-366. [CrossRef]

26. Vassallo, G.A.; Tarli, C.; Rando, M.M.; Mosoni, C.; Mirijello, A.; Agyei-Nkansah, A.; Antonelli, M.; Sestito, L.; Perotti, G.; Di Giuda, D.; et al. Liver transplantation in patients with alcoholic liver disease: A retrospective study. Alcohol Alcohol. 2018, 53, 151-156. [CrossRef]

27. Marroni, C.A.; de Medeiros Fleck, A., Jr.; Fernandes, S.A.; Galant, L.H.; Mucenic, M.; de Mattos Meine, M.H.; Mariante-Neto, G.; de Mello Brandão, A.B. Liver transplantation and alcoholic liver disease: History, controversies, and considerations. World J. Gastroenterol. 2018, 24, 2785-2805. [CrossRef]

28. Mathurin, P.; Hadengue, A.; Bataller, R.; Addolorato, G.; Burra, P.; Burt, A.; Caballeria, J.; Cortez-Pinto, H.; Day, C.P.; Forrest, E.H.; et al. EASL clinical practical guidelines: Management of alcoholic liver disease. J. Hepatol. 2012, 57, 399-420. [CrossRef]

29. Barrio, P.; Teixidor, L.; Rico, N.; Bruguera, P.; Ortega, L.; Bedini, J.L.; Gual, A. Urine ethyl glucuronide unraveling the reality of abstinence monitoring in a routine outpatient setting: A cross-sectional comparison with ethanol, self report and clinical judgment. Eur. Addict. Res. 2016, 22, 243-248. [CrossRef]

30. Skipper, G.E.; Weinmann, W.; Thierauf, A.; Schaefer, P.; Wiesbeck, G.; Allen, J.P.; Miller, M.; Wurst, F.M. Ethyl glucuronide: A biomarker to identify alcohol use by health professionals recovering from substance use disorders. Alcohol Alcohol. 2004, 39, 445-449. [CrossRef]

31. Wetterling, T.; Dibbelt, L.; Wetterling, G.; Göder, R.; Wurst, F.; Margraf, M.; Junghanns, K. Ethyl glucuronide (EtG): Better than breathalyser or self-reports to detect covert short-term relapses into drinking. Alcohol Alcohol. 2014, 49, 51-54. [CrossRef]

32. Arnts, J.; Vanlerberghe, B.T.K.; Roozen, S.; Crunelle, C.L.; Masclee, A.A.M.; Olde-Damink, S.W.M.; Heeren, R.M.A.; van Nuijs, A.; Neels, H.; Nevens, F.; et al. Diagnostic accuracy of biomarkers of alcohol use in patients with liver disease: A systematic review. Alcohol. Clin. Exp. Res. 2021, 45, 25-37. [CrossRef] [PubMed]

33. Stewart, S.H.; Koch, D.G.; Burgess, D.M.; Willner, I.R.; Reuben, A. Sensitivity and specificity of urinary ethyl glucuronide and ethyl sulfate in liver disease patients. Alcohol. Clin. Exp. Res. 2013, 37, 150-155. [CrossRef]

34. Fleming, M.F.; Smith, M.J.; Oslakovic, E.; Lucey, M.R.; Vue, J.X.; Al-Saden, P.; Levitsky, J. Phosphatidylethanoldetects moderate-toheavy alcohol use in liver transplant recipients. Alcohol. Clin. Exp. Res. 2017, 41, 857-862. [CrossRef]

35. Addolorato, G.; Vassallo, G.A.; Mirijello, A.; Gasbarrini, A. Diagnosis and management of alcohol use disorder in patients with liver disease: Lights and shadows. Neurotherapeutics 2020, 17, 127-141. [CrossRef]

36. Andresen-Streichert, H.; Beres, Y.; Weinmann, W.; Schröck, A.; Müller, A.; Skopp, G.; Pischke, S.; Vettorazzi, E.; Lohse, A.; Nashan, B.; et al. Improved detection of alcohol consumption using the novel marker phosphatidylethanol in the transplant setting: Results of a prospective study. Transpl. Int. 2017, 30, 611-620. [CrossRef] 